\title{
Alpha-Band Brain Oscillations Shape the Processing of Perceptible as well as Imperceptible Somatosensory Stimuli during Selective Attention
}

\author{
№rman Forschack, ${ }^{1,2}$ - Till Nierhaus, ${ }^{1,3}$ Matthias M. Müller, ${ }^{2}$ and Arno Villringer ${ }^{1,4}$ \\ ${ }^{1}$ Max Planck Institute for Human Cognitive and Brain Sciences, 04103 Leipzig, Germany, ${ }^{2}$ Department of Psychology, University of Leipzig, 04109 Leipzig, \\ Germany, ${ }^{3}$ Neurocomputation and Neuroimaging Unit, Department of Education and Psychology, Freie Universität Berlin, 14195 Berlin, Germany, \\ and ${ }^{4}$ Mind-Brain-Body Institute, Berlin School of Mind and Brain at the Humboldt-Universität zu Berlin, 10117 Berlin, Germany
}

Attention filters and weights sensory information according to behavioral demands. Stimulus-related neural responses are increased for the attended stimulus. Does alpha-band activity mediate this effect and is it restricted to conscious sensory events (suprathreshold), or does it also extend to unconscious stimuli (subthreshold)? To address these questions, we recorded EEG in healthy male and female volunteers undergoing subthreshold and suprathreshold somatosensory electrical stimulation to the left or right index finger. The task was to detect stimulation at the randomly alternated cued index finger. Under attention, amplitudes of somatosensory evoked potentials increased 50-60 ms after stimulation (P1) for both suprathreshold and subthreshold events. Prestimulus amplitude of peri-Rolandic alpha, that is mu, showed an inverse relationship to P1 amplitude during attention compared to when the finger was unattended. Interestingly, intermediate and high amplitudes of mu rhythm were associated with the highest P1 amplitudes during attention and smallest P1 during lack of attention, that is, these levels of alpha rhythm seemed to optimally support the behavioral goal ("detect" stimuli at the cued finger while ignoring the other finger). Our results show that attention enhances neural processing for both suprathreshold and subthreshold stimuli and they highlight a rather complex interaction between attention, Rolandic alpha activity, and their effects on stimulus processing.

Key words: electroencephalography; linear mixed effects modeling; mu-alpha oscillations; somatosensory evoked potentials; spatial selective attention; subthreshold electrical stimulation

Significance Statement

Attention is crucial in prioritizing processing of relevant perceptible (suprathreshold) stimuli: it filters and weights sensory input. The present study investigates the controversially discussed question whether this attention effect extends to imperceptible (subthreshold) stimuli as well. We found noninvasive EEG signatures for attentional modulation of neural events following perceptible and imperceptible somatosensory stimulation in human participants. Specifically, stimulus processing for both kinds of stimulation, subthreshold and suprathreshold, is enhanced by attention. Interestingly, Rolandic alpha rhythm strength and its influence on stimulus processing are strikingly altered by attention most likely to optimally achieve the behavioral goal.

\section{Introduction}

Attention is "a mechanism by which information relevant to a perceptual decision is filtered or weighted, in the service providing the observer with the most efficient and accurate interpreta-

Received Aug. 15, 2016; revised May 12, 2017; accepted May 17, 2017.

Author contributions: N.F., T.N.,M.M.M., and A.V. designed research; N.F. and T.N. performed research; N.F., T.N., M.M.M., and A.V. contributed unpublished reagents/analytic tools; N.F. analyzed data; N.F., T.N., M.M.M., and A.V. wrote the paper.

This work was supported by the Deutsche Forschungsgemeinschaft, (graduate school GRK 1182 "Mechanisms of Attention"). We thank Sylvia Stasch for excellent technical assistance, Kathleen Wiencke for essential advice on linear mixed modeling, and Birol Taskin for helpful comments on the paper.

The authors declare no competing financial interests. tion of the local sensory environment" (Summerfield and Egner, 2014). It is well known that attention facilitates conscious perception across sensory domains (Dehaene et al., 2006; Schröger et al., 2015), as indexed by its well documented influence on evoked potentials, evoked fMRI/PET signals, or oscillatory activity [somatosensory-evoked potentials (SEPs): Desmedt and Robertson, 1977; Zopf et al., 2004; Schubert et al., 2008; visually evoked

Correspondence should be addressed to either Norman Forschack or Arno Villringer, Max Planck Institute for Human Cognitive and Brain Sciences, Department of Neurology, Stephanstraße 1a, 04103 Leipzig, Germany. E-mail: forschack@cbs.mpg.de or villringer@cbs.mpg.de.

DOI:10.1523/JNEUROSCI.2582-16.2017

Copyright $\odot 2017$ the authors $\quad 0270-6474 / 17 / 376983-12 \$ 15.00 / 0$ 

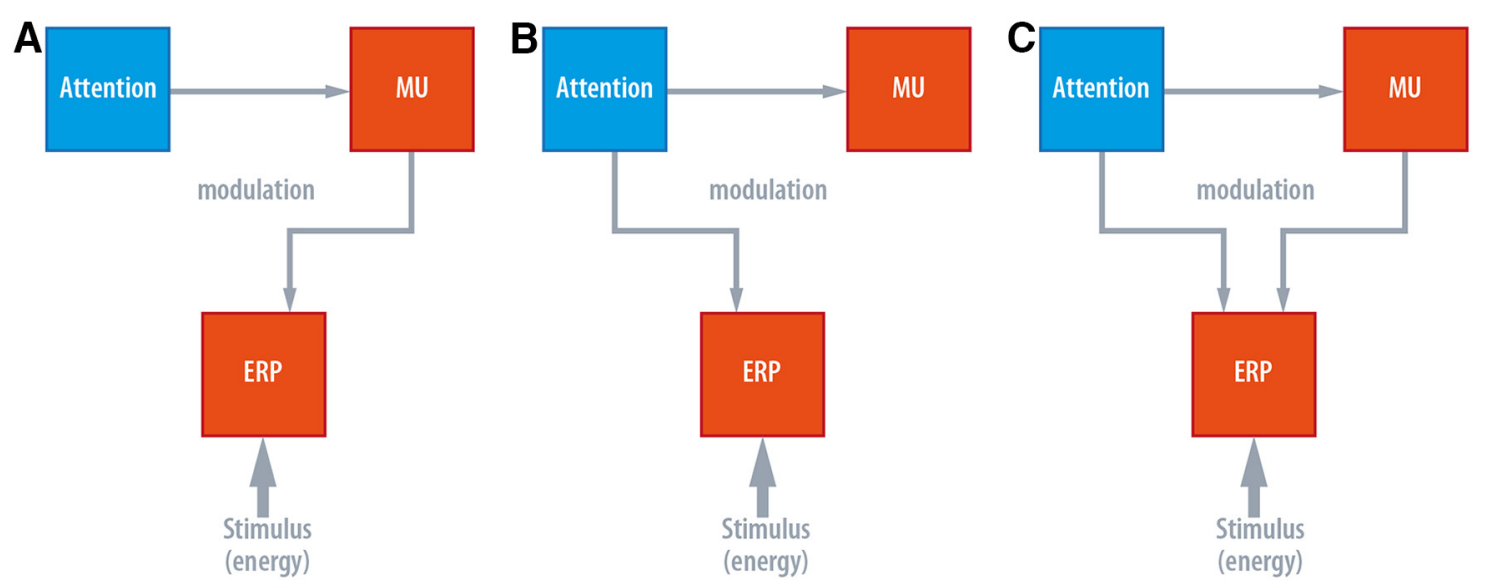

Figure 1. Three different models of possible relationships between attention, prestimulus somatosensory alpha (mu), and ERP/SEP amplitude. $\boldsymbol{A}$, The mediator model: the effect of attention is mediated by prestimulus mu. $\boldsymbol{B}$, Attention influences both prestimulus mu and SEP amplitude, but SEP modulation is independent of prestimulus mu amplitude (independence model). $\boldsymbol{C}$, The interaction model: the relationship between prestimulus mu and SEP amplitude depends on the attentional state.

potentials: Eason et al., 1969; auditory-evoked potentials: Hillyard et al., 1973; somatosensory fMRI: Johansen-Berg et al., 2000; Goltz et al., 2013, 2015; visual fMRI: Gandhi et al., 1999; auditory fMRI: Alho et al., 1999; PET: Wu et al., 2007; brain rhythms: Clayton et al., 2015].

However, attention processes do not necessarily depend on conscious percepts (Koch and Tsuchiya, 2007; Kentridge et al., 2008; Graziano, 2013). Attention effects on subliminal processing have been shown in the visual modality (van Boxtel et al., 2010; Watanabe et al., 2011; de Haan et al., 2015), but based on paradigms involving masking or extinction. However, subliminal brain responses to masked stimuli have been shown to be interrupted by the brain responses of the mask (Lamme et al., 2002; Fahrenfort et al., 2007), which may preclude observations unique to genuine processes below consciousness elicited by unmasked subliminal stimulation. Neural markers for cerebral processing of somatosensory stimuli below absolute detection threshold (i.e., stimulation is never reported: subthreshold) have been described previously. However, these were only based on invasive studies using subdural electrodes under clinical conditions (Libet et al., 1967; Ray et al., 1999) limiting potential investigations. Recently, we have identified an event related potential in response to subthreshold stimulation (a positive deflection occurring $\sim 60$ ms after stimulation: P1; Nierhaus et al., 2015). First, these findings allowed us to address the question whether attention also modulates neural processing of subthreshold, that is, unconsciously processed, somatosensory stimuli as it has been suggested previously (Dehaene et al., 2006). Second, we examined the role of alpha-band brain oscillation in relation to the effect of attention. Although several studies conclude that attention decreases the amplitude of baseline (prestimulus) alpha rhythm (Palva and Palva, 2007; Jones et al., 2010; Anderson and Ding, 2011; Haegens et al., 2011a, b; Jensen et al., 2012), evidence for the relationship of prestimulus alpha power on the amplitudes of evoked potentials is ambiguous. Both linear (Nikouline et al., 2000b; Reinacher et al., 2009; Roberts et al., 2014) and nonlinear relationships (Zhang and Ding, 2010; Anderson and Ding, 2011) have been reported. Although the latter findings challenge the view of alpha activity directly reflecting cortical excitation (Jensen and Mazaheri, 2010; Foxe and Snyder, 2011), one might still argue that the variation of prestimulus alpha activity in spatial attention leads to a modulation of evoked activity (Jones et al., 2010; Haegens et al., 2011a, 2012; Jensen et al., 2012). Consequently, with attention, the highest P1 ampli- tudes should be accompanied by low prestimulus alpha power in the case of a linear relationship, or alternatively, by intermediate power ranges in the nonlinear case (Anderson and Ding, 2011).

Here we investigated the role of prestimulus peri-Rolandic alpha, that is, sensorimotor alpha or simply mu, amplitude and its (modulatory) impact on central stimulus processing by means of EEG recordings and event-related potentials in humans. We presented subthreshold and, at a lesser number, irregularly intermingled suprathreshold single electrical current pulses to the index fingers of the left or the right hand during variation of spatial attention. Thus, we tested whether or not attention and alpha activity operate analogously for subthreshold and suprathreshold stimuli. Figure 1 illustrates potential functional relationships between attention, mu rhythm activity, and evoked brain activity.

\section{Materials and Methods}

\section{Participants}

The study was approved by the local ethics committee. Before participation, all volunteers underwent a comprehensive neurological examination. They had no history of neurological or psychiatric diseases and were not on any medication. Forty healthy volunteers participated (age range 20-32 years, mean $25.1 \pm 2.9$ years SD; 20 females); all were righthanded (laterality score according to the Oldfield questionnaire: mean $91.6 \pm 10.2 \mathrm{SD}$, over a range of -100 (fully left-handed) to 100 (fully right-handed); Oldfield, 1971). Data of three subjects were discarded due to defective or artifactual EEG recordings, so in total 37 datasets were analyzed.

In an additional psychophysics study (see below) we invited 14 subjects (age range 22-32 years, mean $26.7 \pm 2.8$ years SD; 7 females) that were all right-handed (mean $90.4 \pm 11.7 \mathrm{SD}$ ) and included in the analysis.

\section{Experimental procedures}

Somatosensory stimulation and task design. Electrical finger nerve stimulation was performed by constant-current stimulators (DS7A, Digitimer) applying single current square wave pulses (duration $200 \mu \mathrm{s}$ ), controlled by the stimulation software "Presentation" (Neurobehavioral Systems). A pair of steel wire ring electrodes was attached to the middle (anode) and the proximal (cathode) phalanx of the left and right index finger. A trained experimenter manually assessed absolute detection thresholds, which were defined as the lowest current intensity (for continuous $7 \mathrm{~Hz}$ stimulation) at which participants just reported a sensation. A rough estimate of this detection threshold was derived by applying one trial of method of limits with ascending intensities separately for the left and right index finger (just before the first block). To control for threshold stability and to readjust stimulus intensities in case of a threshold shift, we precisely determined ( $0.05 \mathrm{~mA}$ precision) absolute detection thresh- 
Table 1. Stimulation conditions and parameters

\begin{tabular}{lll}
\hline & Stimulation left & Stimulation right \\
\hline Subthreshold & ISI 3.2 s, \pm 1.0 s jitter & - \\
& 936 stimuli, 36 per block & \\
& $1.48 \mathrm{~mA}$ (M), 0.45 mA (SD) & \\
& $15 \%$ below absTH & \\
Suprathreshold & Pseudorandomized & Pseudorandomized \\
& 52 stimuli, up to 4 per block & 52 stimuli, up to 4 per block \\
& 2.94mA (M), 0.65mA (SD) & $3.05 \mathrm{~mA}$ (M), 0.66mA (SD) \\
& $28-200 \%$ above absTH & 24-192\% above absTH \\
& detected: 79\% (M), 41\% (SD) & detected: 83\% (M), 37\% (SD)
\end{tabular}

Intensity of stimuli is given in milliampere (mA). absTH, absolute detection threshold; M, Mean; SD, Standard Deviation.

olds before each EEG acquisition block using a yes/no detection procedure [one-alternative forced-choice (1AFC), not included in the EEG recording of $\sim 8$ min duration per block; Kingdom and Prins, 2009]. Thus, the experimenter presented current intensities (at $7 \mathrm{~Hz}$ for $1 \mathrm{~s}$ each) around the previously estimated rough detection threshold (or the previous precise threshold for block numbers $>1$ ) as well as catch/ blank trials ( $20 \%$ of all $1 \mathrm{AFC}$ trials) to account for guessing/ liberal response criterion (from our experience, false alarm rates are largely 0 for this specific procedure and this was also true for the current threshold assessments). Participants responded with "yes" if they felt a stimulus and "no" if otherwise. Intensities were selected adaptively, according to the participant's responses; for example, if an observer perceived a given stimulus, intensity for the following trial was usually (but not necessarily) decreased and vice versa. However, once in a while a stimulus at a high intensity was presented reminding the observer what to "look" for. The range of applied intensities was also decreased successively until an intensity was identified that satisfied the above definition of an absolute detection threshold (absTH), that is, an intensity that enables a stimulus to be just discriminated from its null (Kingdom and Prins, 2009). For instance, if an observer reliably responded no to a given intensity " $x$ " but reported to perceive the next higher intensity " $x+0.05 \mathrm{~mA}$ " on a fraction of the trials, the latter intensity value served as absTH (30-60 trials which took $\leq 5 \mathrm{~min}$ ). To ensure imperceptibility of subthreshold stimuli during the entire experiment, subthreshold stimulation intensity (left finger) was set to $15 \%$ below absolute detection threshold and tested to be reliably imperceptible when presented as single pulses. Additionally, we conducted an independent 1AFC psychophysics experiment (see Psychophysics control experiment) that validates that this thresholding procedure yields undetectable subthreshold intensities (i.e., 0 D-prime sensitivity). The intensity of suprathreshold stimulation was adjusted within a range of $25-200 \%$ above detection threshold (Table 1) depending on the participants' subjective report of experiencing a clear (i.e., conscious) isointense but innocuous percept on both fingers. During experimental blocks, subthreshold and suprathreshold stimulation intensities were kept constant and subthreshold stimulation was applied to the left hand only (Fig. 2). Participants were instructed to respond to perceived stimuli only to the cued hand (left or right) via button press with their right foot.

Accordingly, the following stimulation conditions were presented during the experiment: subthreshold stimulation to the left hand that was either attended ("subthreshold left attended" condition) or unattended ("subthreshold left unattended" condition) and four conditions where suprathreshold stimulation to the left or the right hand was attended or unattended, respectively ("suprathreshold left attended", "suprathreshold left unattended", "suprathreshold right attended", "suprathreshold right unattended" conditions). In the offline analysis we only focused on left hand stimulation (data on right hand stimulation was not considered; Table 1).

EEG acquisition. During stimulation blocks, EEG was recorded continuously from 32 scalp channels (international 10-20 system; actiCap, BrainAmp, Brain Products): midfrontal electrode (FCz) as reference, sternum electrode as ground, impedances $\leq 5 \mathrm{k} \Omega$ for all channels, sampling frequency $1 \mathrm{kHz}$, a low-pass finite impulse response filter $(250 \mathrm{~Hz})$ was applied before downsampling EEG time courses to $500 \mathrm{~Hz}$.
To allow for reliable detection of SEPs and Rolandic rhythms, stimuli were presented at comparatively long interstimulus intervals, that is, subthreshold stimuli at a mean interstimulus interval of $3.2 \mathrm{~s}$ (jitter of $\pm 1000 \mathrm{~ms}$ during a block of $\sim 2 \mathrm{~min}$, in total 26 blocks, i.e., 936 trials per participant). Moreover, in each block no or up to four suprathreshold stimuli were presented pseudorandomly to the left or the right hand (total 52 suprathreshold stimuli on either hand). Participants were instructed to report perception of stimuli only when presented to the cued side and to "ignore" stimuli to the non-cued hand. Finally, two additional blocks were appended comprising only suprathreshold stimulation of the left and right index finger without attention task (stimulation frequency every $1.6 \pm 0.3 \mathrm{~s}$, resulting in 360 trials, $\sim 5$ min block duration), so we obtained a sufficient number of trials with suprathreshold stimulation (for a criterion-guided independent component selection in later steps of the analysis procedure, see below).

\section{EEG data analysis}

Preprocessing. EEG data analysis was performed offline using custombuilt MATLAB scripts (MathWorks, RRID:SCR_001622) and toolbox algorithms from EEGLAB (Delorme and Makeig, 2004, RRID:SCR_007292). Individual datasets underwent an independent component analysis (ICA; infomax extended) both to remove sources of ocular and muscle artifacts (Li et al., 2006; Delorme et al., 2012) and to select components resembling mu activity sources. Before ICA, datasets were prepared applying the following procedures: training datasets for ICA were high-pass filtered with $1 \mathrm{~Hz}$, all blocks were concatenated, contiguous epochs of $1 \mathrm{~s}$ were extracted, screened for nonstereotypical artifacts, and rejected if contaminated. Then, an initial ICA was performed that semiautomatically removed artifactual epochs using improbable data estimation on single and over all components (function "pop_jointprob"; Delorme et al., 2007). The resulting datasets were submitted to a second ICA: the new set of components was visually inspected, artifactual components were identified (i.e., correlation with EOG channel $>0.8$, blink or eye movement typical topographies and IC source activity, abnormal frequency spectrum, i.e., high-frequency or line noise, focal topographies), and only the unmixing and sphering matrices of artifact-free components were forward-projected to the unfiltered datasets for the subsequent analysis steps.

SEPs. Epochs were defined ranging from -1200 to $2200 \mathrm{~ms}$ relative to stimulus onset $(t=0)$, from which the individual epoch mean was subtracted. Epochs exceeding the joint logarithmic probability of 4.5 or 2.5 SD within or across independent components, respectively, were discarded after manually reviewing the alleged artifactual epochs (Delorme et al., 2007). This resulted in an average number of 420 trials ( \pm 14 SD) for attending left subthreshold stimulation and 420 trials ( \pm 13 SD) for "ignoring" left subthreshold stimulation (i.e., attending right); 23 trials $( \pm 3$ SD) for attending left suprathreshold stimulation and 24 trials $( \pm 2 \mathrm{SD})$ for ignoring left suprathreshold stimulation. In a next step, data were low-pass filtered applying the standard EEGLAB Hamming windowed sinc finite impulse response filter (zero-phase FIR, pass band edge: $41 \mathrm{~Hz}$, high cutoff $(-6 \mathrm{~dB}): 46.125 \mathrm{~Hz}$, filter order 162; Widmann et al., 2015). Trials with behavioral responses following or preceding subthreshold stimulation were very rare and excluded from further analysis (only 8 participants responded to subthreshold stimulation once or twice out of 960 trials).

Topographical analysis via isocontour voltage maps $50-60 \mathrm{~ms}$ poststimulation revealed that contralateral somatosensory areas were most sensitive to somatosensory stimulation compared with prestimulus baseline (paired $t$ tests, fdr-corrected). Therefore, statistical analysis of SEP amplitude was performed on electrode CP4 (i.e., in close vicinity to somatosensory cortex contralateral to stimulation site that has been found previously to exert maximum SEP amplitudes; Nierhaus et al., 2015), by averaging the amplitude of time points $50-60 \mathrm{~ms}$ postsubthreshold stimulation (P60) and performing a paired two-tailed $t$ test $(p<0.05)$ against baseline $(-100$ to $-20 \mathrm{~ms}$ relative to stimulus onset; Zhang and Ding, 2010). The definition of time range of interest was hypothesis-driven, because previously we only found the P60 and no additional components to be indicative of subthreshold somatosensory processing (Nierhaus et al., 2015). A known marker for early attention 


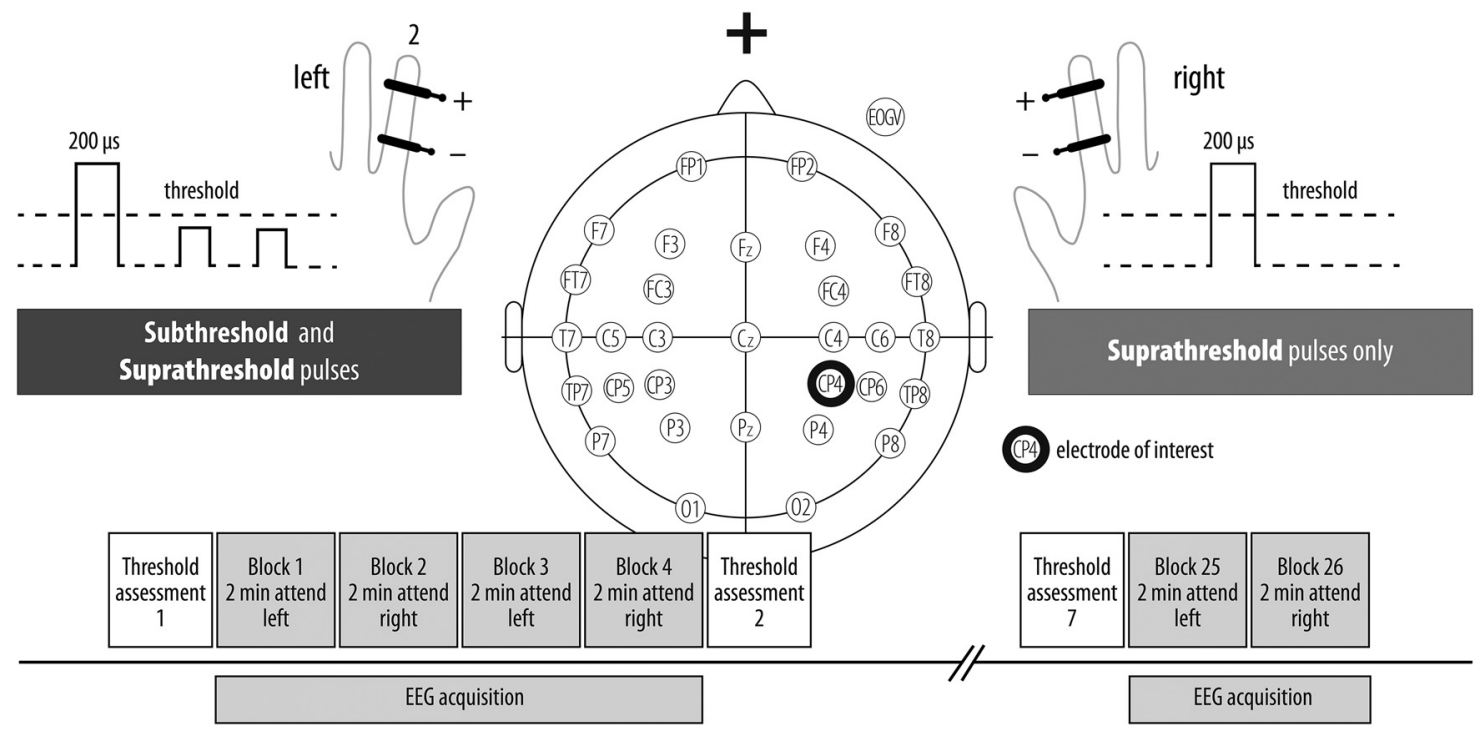

Figure 2. Experimental setup and stimulation paradigm. Forty subjects received 936 imperceptible electrical pulses to the left index finger via the DS7A (Digitimer) over 26 two-minute blocks. In each block, up to four perceptible stimuli were randomly presented to the left or right hand (in total 104). Absolute detection thresholds were determined initially using the method of limits (one ascending trial) and a subsequent yes/no adaptive detection task consisting of 30-60 trials (maximally 5 min, including blank/ catch trials) and subsequently every four measurement blocks.

modulation of suprathreshold stimulation, the P50-N80 complex (Michie et al., 1987), was extracted by subtracting averaged amplitudes $\sim 80-100 \mathrm{~ms}$ (N80) from averaged amplitudes $\sim 50-60 \mathrm{~ms}$ (P50) poststimulus. As for the P60, the amplitude of the P50N80 complex was tested between attention conditions by means of paired $t$ test. To test for the presence of further evoked potentials, each sample point of a $400 \mathrm{~ms}$ poststimulus epoch was successively compared with the mean prestimulus baseline value (paired $t$ tests $(p<0.05)$, multiple-comparisons correction with fdr, data not shown).

Rolandic rhythms. To discern Rolandic rhythms from dominating occipital alpha activity, a preselection of "central" ICA components was performed before trial segmentation. For this purpose, all blocks (including the pure suprathreshold stimulation blocks) were concatenated to run to run individual ICA. As done by Nierhaus et al. (2015), we selected Rolandic background rhythms according to three criteria for each participant: (1) a central localization; (2) two peaks in the power-spectrum, at alpha $(8-15 \mathrm{~Hz})$ and beta $(16-30 \mathrm{~Hz})$ frequency bands, respectively; and (3) a pronounced power reduction of these bands after suprathreshold stimulation. Using this procedure, $1-4$ (mean $2 \pm 1$ SD) ICs per participant were selected (all 37 participants showed at least one right hemispheric lateralized mu component, 24 showed additionally a left lateralized mu component). Only these components were forward projected and included in further analysis of somatosensory oscillatory activity. After forward projection of the "central" ICs and segmentation of subthreshold and suprathreshold epochs as defined above $(-1200$ to $2200 \mathrm{~ms}$ ), a wavelet analysis was performed for frequencies from 6 to 30 $\mathrm{Hz}$ in $1 \mathrm{~Hz}$ increments to allow for a time-resolved frequency analysis of event-related power modulation. The wavelet transformation was performed on each single trial using wavelet cycle lengths from 4 to 7 cycles increasing with frequency in linear steps. Subsequently, the resulting time-frequency response was averaged over trials.

Statistical analysis was performed on electrode CP4 (located over SI contralateral to the stimulation site on the left hand and also showing maximal weights in independent component maps) by means of twotailed paired $t$ tests of poststimulus time points against frequency-specific baseline average (p-level was fdr-corrected with $q=0.05$; Genovese et al., 2002; with a prestimulus baseline of -700 to $-200 \mathrm{~ms}$ ). To test the condition contrast across poststimulus values, we compared baseline-normalized alpha band values $(8-15 \mathrm{~Hz})$ for attended and unattended subthreshold and suprathreshold stimulation conditions (fdr-corrected).

Regression of SEPs and behavior on prestimulus mu amplitude. To test the relationship between oscillatory brain state (mu amplitude) and stimulus processing (SEP amplitude and hit rates), we pooled trials across attention conditions on participant level and calculated the average mu amplitude (estimated by a $10 \mathrm{~Hz}$ wavelet kernel with 4.9 cycles) for each trial 300-200 ms before stimulus onset. These values were reordered from smallest to largest amplitude and assembled into five consecutive bins (indexed by 1-5) with $50 \%$ overlap of trials for successive bins. Afterward, we separated the trials in each bin according to the attention condition. This binning procedure serves as normalization and compensates for interindividual differences in absolute mu amplitude. Importantly, this also yields comparable mu amplitudes between attention conditions for any of these bins (tested via two-way repeated-measure ANOVA with factors power bin ( 5 levels) and attention ( 2 levels) and mu amplitude as dependent variable). Effect sizes were quantified as generalized $\eta$ squared (Bakeman, 2005). It has to be noted, however, that the number of trials within each bin may differ between attention conditions, which was tested by paired $t$ tests [average number and SEM of trials per bin 1-5 for subthreshold attended: 143 (9), 143(9), 140 (8), 139 (8), 137 (10); subthreshold unattended: 138 (10), 137 (9), 140 (7), 141 (7), 144 (9); suprathreshold attended: 8 (2), 8 (1), 8 (2), 8 (2), 7 (2); suprathreshold unattended: 8 (1), 8 (2), 8 (2), 8 (2), 8 (2); significant between attention condition trial number differences: subthreshold bin 2 $\left(t_{(36)}=2.05, p=0.048\right)$; subthreshold bin $5\left(t_{(36)}=-2.3, p=0.027\right)$; remaining tests yield absolute $t$ scores $<1.8$ ]. We then calculated the subthreshold and suprathreshold SEP for each bin and attention condition, and extracted the amplitude of the key component (P1) as described in the SEPs section. Bin-wise hit rates (HRs) were calculated for the suprathreshold left attended condition.

To assess the grand-average relationship between SEP amplitude and prestimulus mu amplitude for each attention condition, we calculated a standard linear regression with mu amplitude bins serving as predictor [quadratic and linear, including an intercept, i.e., the ordinate (SEP amplitude) offset] and bin SEP amplitude (and HR) serving as regressor (in fact, there are 5 values that the predictor can attain). However, this approach has some substantial drawbacks as it obscures intersubject variability. Factors like vigilance regulation patterns (Bekhtereva et al., 2014), individual behavior adjustments, and threshold variations, which are deemed to be random across the sample, may influence the relationship between experimentally relevant factors. With linear mixed-effects modeling (LMM), we acknowledge between- and within-participant variations in the data from the model's fixed-effect estimates (i.e., the grand-average effect). We conducted the LMM analysis in R (R Core Team, 2014, RRID: SCR_001905) within the lme4 framework proposed by Bates et al. (2014). For our LMM fixed effects, we estimated intercept and weights for a quadratic and linear mu amplitude predictor just as for the standard 
Table 2. LMM testing the relationship between prestimulus mu amplitude bin and SEP amplitude for each attention condition separately (model no. 1-12)

\begin{tabular}{|c|c|c|c|c|}
\hline Condition & Model №. & Lmer syntax & Likelihood & LRT \\
\hline \multirow[t]{3}{*}{ Subthreshold attended } & (1) & P60 1 $+(1 \mid$ Subject $)$ & -177.49 & \\
\hline & (2) & P $60 \sim 1+$ Bin $+(1+$ Bin|Subject $)$ & -170.52 & $\chi^{2}=13.94^{* *}$ \\
\hline & (3) & $P 60 \sim 1+\operatorname{Bin}+\mathrm{I}\left(\operatorname{Bin}^{\wedge} 2\right)+\left(1+\operatorname{Bin}+\mathrm{I}\left(\operatorname{Bin}^{\wedge} 2\right) \mid\right.$ Subject $)$ & -166.37 & $\chi^{2}=8.31^{*}$ \\
\hline \multirow[t]{3}{*}{ Subthreshold unattended } & (4) & As (1), & -176.32 & \\
\hline & (5) & (2), & -170.67 & $\chi^{2}=11.29^{* *}$ \\
\hline & (6) & (3), respectively & -161.3 & $\chi^{2}=18.73^{* * *}$ \\
\hline \multirow[t]{3}{*}{ Suprathreshold attended } & (7) & P50 1 + (1|Subject $)$ & -439.65 & \\
\hline & (8) & P50 1 + Bin $+(1+$ Bin|Subject $)$ & -434.98 & $\chi^{2}=9.34^{*}$ \\
\hline & (9) & $P 50 \sim 1+\operatorname{Bin}+I\left(\operatorname{Bin}^{\wedge} 2\right)+\left(1+\operatorname{Bin}+I\left(B i{ }^{\wedge} 2\right) \mid\right.$ Subject $)$ & -426.65 & $\chi^{2}=16.7^{* *}$ \\
\hline \multirow[t]{3}{*}{ Suprathreshold unattended } & (10) & As (7), & -458.01 & \\
\hline & (11) & (8), & -452.7 & $\chi^{2}=10.7^{* *}$ \\
\hline & (12) & (9), respectively & -435 & $\chi^{2}=35.34^{* * *}$ \\
\hline
\end{tabular}

Likelihood depicts the models' log transformed likelihood, bigger is better, i.e., the more likely the model. LRT is the likelihood ratio test comparing two models for the same dataset [Bigger models (more parameters) are compared with respective smaller ones]. This returns a $\chi^{2}$ value. However, $p$ values are based on parametric bootstrapping $\left(10,000\right.$ simulations; Halekoh and Højsgaard, 2014): ${ }^{*}<0.05-0.01, * *<0.01-0.001, * * *<0.001-0$.

regression in the fixed effects part (i.e., the grand average relationship, intersubject variation ignored). Additionally, the same predictor structure was used for the random effects part of the model with participant as the grouping variable. This has the advantage of (1) being the maximal random effect structure required for hypothesis testing as claimed by Barr et al. (2013), and (2) it yields participant-specific deviation predictions from the fixed effects within a single model estimation instead of multiple by-participant ordinary regressions (Baayen et al., 2008; Zhang and Ding, 2010). LMMs are defined in the following form: outcome $\sim$ predictor(s) + (predictor $(\mathrm{s}) \mid$ subject), which will fit predictors of the fixed effect part (next to the " $\sim$ ") and predictors of the random effects part (in brackets) grouped by a factor for which the predictors vary randomly, in our case, participant. All in all, we computed four LMMs that regressed SEP amplitude on prestimulus mu amplitude bin separately for each attention (attended, unattended) and stimulation condition (P1 amplitude for subthreshold and suprathreshold stimulation) and one LMM in which hit rate was the dependent variable. To check the significance of each of the five models and the relevance of specific predictors, maximumlikelihood ratio test statistics (which account for model complexity) between the complete (all predictors) and reduced models (one model assuming no relationship, i.e., only the intercept serves as predictor, and one model assuming a linear relationship; Table 2 shows detailed model definitions) were parametrically bootstrapped with 10,000 simulations (pbkrtest-package by Halekoh and Højsgaard, 2014). All these models describe the relationship between mu amplitude and SEP amplitudes (and HR) but do not consider the subjective attentional state (see next section), because fitting was done separately for each attention condition.

Assessment of the relationship between prestimulus mu amplitude, somatosensory evoked potential, and attention. How does attention affect prestimulus mu amplitude and SEP amplitudes? Is a putative attention effect on SEP amplitude mediated (or indexed) by prestimulus mu? Does attention affect both prestimulus mu and SEP amplitudes independently? Or do responses of these variables depend on each other, or, in other words, do they interact? To evaluate these questions, we tested three different types of possible relationships depicted in Figure 1. For this purpose, following LMMs were fitted to data including both attention conditions, not separately as in the previous paragraph.

If the influence of attention is solely mediated by prestimulus mu amplitude (Fig. 1A, "mediator model"), any form of relation between prestimulus mu amplitude and SEP amplitude will not be differentiable between the two attention conditions. Therefore, we fitted two LMMs to subthreshold and suprathreshold SEP amplitudes (dependent variable) with intercept, linear, and quadratic predictor of prestimulus mu amplitude both for fixed and random effects grouped by participant (in fact, the same model definition as for single attention condition fits above), neither of which including attention as predictor in the fixed nor random effects part. In other words, it is assumed that the attention effect on SEP amplitude is completely reflected in the variation of prestimulus mu amplitude.

However, if the effect of attention on SEP amplitudes is independent from an attention effect on prestimulus mu amplitude (Fig. 1B, "inde- pendence model"), a significant relationship between prestimulus mu amplitude and SEP amplitudes will not be observable. Here, the two LMMs fitted subthreshold and suprathreshold SEP amplitudes with the factors intercept and attention in the fixed effects part and intercept grouped by participant and attention as within-participant factor in the random effects part (Table 2 shows detailed model definitions). In short, the relationship between prestimulus mu amplitude and SEP amplitudes would appear to be flat but SEP amplitudes between attention conditions would differ. (Note that an absence of significant relationships of any sort for the single attention conditions (see previous section) would support the independence model).

Finally, if the type of relationship between prestimulus mu amplitude and SEP amplitudes essentially depends on the subjective state of attention (Fig. 1C, "interaction model"), we will observe different relationships for each attention condition. The LMM definitions to fit subthreshold and suprathreshold SEP amplitudes therefore include the factors intercept, attention, the linear and quadratic mu amplitude predictor, as well as the interaction of the latter and attention in the fixed effect part. The random effects part contains intercept, the linear and quadratic mu amplitude predictor grouped by participant, as well as attention as within-participant factor (see model definitions in Table 2).

Models were evaluated by their ability to explain the data, here maximum-likelihood, and significance was assessed via parametric bootstrapped likelihood ratio tests (10,000 simulations).

\section{Psychophysics control experiment}

To evaluate whether our threshold assessment procedure described above is appropriate for selecting individual subthreshold intensities that are truly imperceptible, we conducted this control experiment to show that sensitivity (i.e., D-prime or $\mathrm{d}^{\prime}$ ) to subthreshold trials is indeed zero. We applied the very same procedure for threshold determination (and determination of subthreshold stimuli) as in the main EEG experiment, and determined $\mathrm{d}^{\prime}$ for seven stimulation intensities along the individual psychometric function for which the absolute detection threshold (absTH) served as reference point. Importantly, the control experiment included 100 catch trials where no stimulation was presented. The remaining stimulation conditions included trials with two subthreshold intensities [ $\operatorname{subTH}(-30 \%): 100$ trials, $\operatorname{subTH}(-15 \%): 100$ trials, i.e., $70 \%$ and $85 \%$ of absTH], the absolute detection threshold intensity (absTH: 60 trials), three near-threshold intensities (NTH: $3 \times 60$ trials) and one suprathreshold intensity (STH 100\%: 60 trials). Participants performed a yes/No detection (1AFC) task. The STH intensity was individually adjusted to be the first that is perceived throughout all trials during a preceding stimulus detection run applying five different above threshold intensities ( 5 repetitions for each, and 5 catch trials) that remained constant for the duration of $2 \mathrm{~min}$ (method of constant stimuli). If no STH intensity could be identified, further stimulus detection runs, for which stimulation intensities were increased by $0.2 \mathrm{~mA}$ each, were conducted until STH criterion was reached. NTH intensities were tuned to $25 \%, 50 \%$, or $75 \%$ of the distance between absolute detection threshold and $100 \%$ STH. 


\section{Results}

We stimulated the left and right index finger with electrical pulses (Table 1) while participants responded to perceived sensations only on the cued side and ignored sensations on the other side (Fig. 2), thus characterizing the effects of attention on central somatosensory stimulus processing.

\section{Behavioral responses}

The resulting average hit and false alarm rates for suprathreshold stimulation of attended left (hit rates: $71.06 \pm 17.88 \%$ S.D, false alarm rates: $0.82 \pm 0.17 \%$ SD) and right index finger (hit rates: $73.76 \pm 17.59 \%$ SD, false alarm rates: $0.66 \pm 0.11 \%$ SD) did not differ significantly $\left(t_{(36)}< \pm 1\right.$ in all cases). The average number of responses to subthreshold stimulation for both attention conditions was negligible ( 2 subjects responded twice, 6 subjects responded once of 480 subthreshold trials).

Participant's sensitivity to subthreshold stimulation trials have furthermore been tested to be reliably zero as can be observed in Figure 3, which shows the results of the additional 1AFC psychophysics experiment. D-prime is not significantly different from zero for the absTH that serves as individual reference value for adjusting subthreshold intensities for each subject to be $15 \%$ and $30 \%$ lower than absTH.

\section{Responses to subthreshold and suprathreshold stimulation evolves differentially over time with respect to SEP and sensorimotor alpha and beta band power}

SEPs in response to left hand somatosensory stimulation were lateralized to the right hemisphere. As in our previous study (Nierhaus et al., 2015), we restricted our analysis to the contralateral hemisphere because only the left index finger received both subthreshold and suprathreshold stimulation. Depending on stimulation intensity (i.e., either above or below detection threshold), we observed different evoked components: for suprathreshold stimulation a P50 was followed by an N80 and at least one later component (P150). For subthreshold stimuli we observed a single early positivity $\sim 60 \mathrm{~ms}, \sim 10 \mathrm{~ms}$ later than the first component for suprathreshold stimuli (Fig. 4).

Regarding mu amplitude, we found opposing effects: a decrease, compared with baseline, after suprathreshold stimulation and an increase after subthreshold stimulation, which confirms our previous findings (Nierhaus et al., 2015). It is noteworthy that in the condition where the left index finger was unattended (attention directed to the right hand), an early increase of mu amplitude (13-15 Hz) and a decrease of beta amplitude (20-23 $\mathrm{Hz}, \sim 150-200 \mathrm{~ms}$ ) following subthreshold left index finger stimulation was prevalent ( $t$ test, fdr-corrected with $p<0.05$ ). When the left index finger was attended, an increase in mu amplitude $(9-10 \mathrm{~Hz})$ and a concomitant decrease in beta amplitude (20-24 $\mathrm{Hz}$ ) occurred, 200-300 ms later (fdr-corrected, $p<0.05$; Fig. 5). When directly comparing the stimulation effect of the averaged somatosensory alpha band $(8-15 \mathrm{~Hz})$ between attention conditions, this temporal dissociation was not significant (fdr-corrected).
Subthreshold and suprathreshold SEPs and prestimulus mu amplitude are modulated by spatial selective attention

We tested the main effect of attention on SEPs for averaged amplitudes 50-60 ms poststimulus. Subthreshold stimulation evoked a P1 at posterior peri-central electrode sites (CP4) that was significantly enhanced when the finger was attended compared with unattended (Fig. $6 A ; t_{(36)}=2.21, p<0.04$ ). This confirms our first hypothesis that attention modulates neural processing of subthreshold, that is, unconsciously "perceived", somatosensory stimuli.

For suprathreshold stimulation, we subtracted averaged amplitudes $\sim 80-100 \mathrm{~ms}$ (N80) from averaged amplitudes $\sim 50-60$ ms (P50) poststimulus onset. The P50-N80 complex (i.e., the peak between $\mathrm{P} 1$ and N1) was significantly increased during the attended compared with the unattended condition (Fig. $6 A ; t_{(36)}=$ 2.22, $p<0.04)$.

As expected, attention modulated overall mu amplitude preceding stimulation, with higher amplitudes contralateral to the unattended side (Fig. $6 B ; t_{(36)}=-2.34, p<0.025$ ).

\section{The relationship between prestimulus mu and SEP amplitude depends on attention}

To investigate the relationship between prestimulus mu amplitude (pre-mu) and SEPs and HRs, we aggregated trials for each attention and stimulation condition (attended or unattended and subthreshold or suprathreshold) separately over five bins of increasing mu amplitude. The procedure resulted in mu amplitude bins with comparable (almost equal) mu amplitude between attention conditions within a given bin (Fig. $6 C b, D b$; see Materials and Methods for details). The repeated-measure ANOVA for binned mu amplitude preceding subthreshold stimulation reveals a significant main effect of both amplitude bin and attention $\left(F_{(4,144)}=1489.6, p[\mathrm{GG}]<0.0001, \eta_{G}^{2}=0.44\right.$ and $F_{(1,36)}=6.7$, $p<0.014, \eta_{G}^{2}=0.00003$, respectively). Post hoc comparisons via paired $t$ tests identified the bin with the highest mu amplitude as the driver of the attention main effect $\left(t_{(36)}=-2.86, p<0.01\right)$. A similar ANOVA, testing binned mu amplitude preceding su- 


\section{Attended}

\section{subthreshold}

$\mathrm{Aa}$
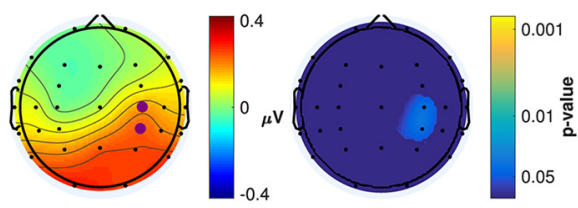

b
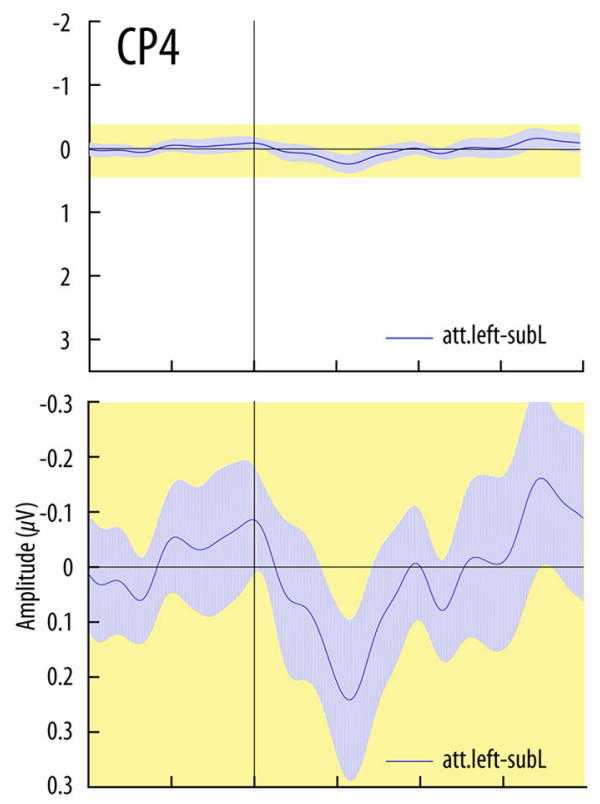

Unattended

C

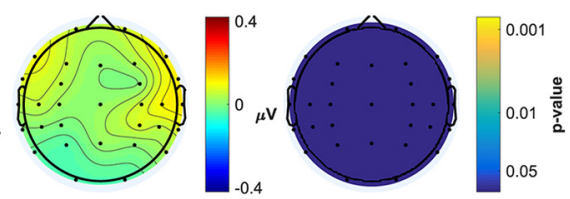

d
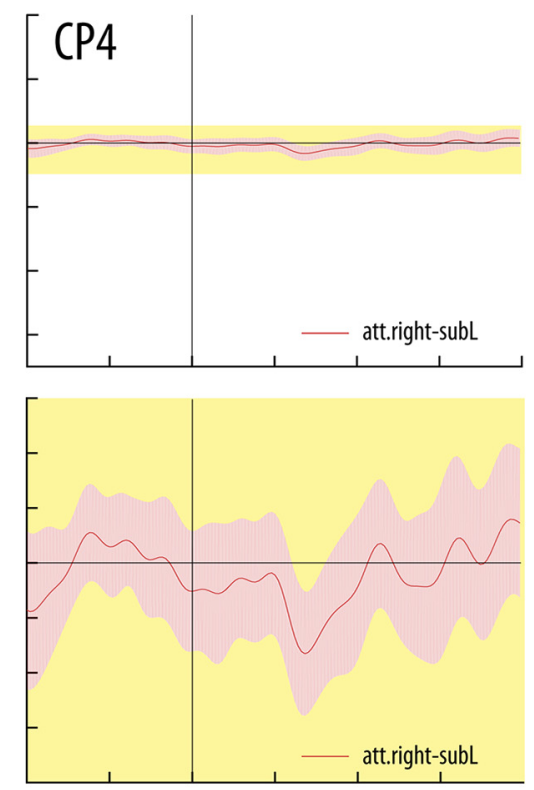

\section{suprathreshold}

\section{$\mathrm{Ba}$}
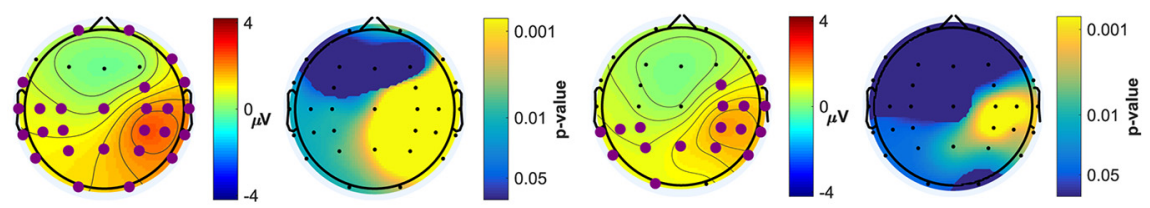

b

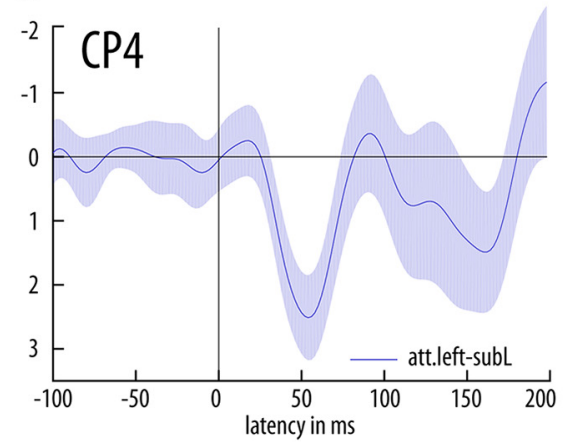

d

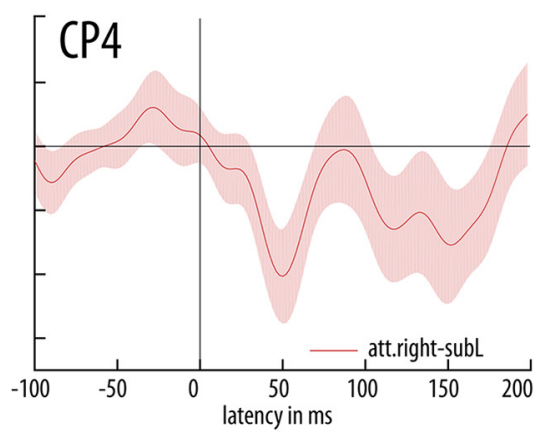

Figure 4. Subthreshold $(\boldsymbol{A})$ and suprathreshold $(\boldsymbol{B})$ isocontour voltage maps and SEPs. Aa, Average voltage topographies for a window of 50-60 ms poststimulus (grand average, GAVG, $n=37$ participants) for the subthreshold left attended condition on the left and topographical $p$ value distribution on the right side ( $t$ tests against baseline -100 to -20 ms prestimulus, fdrcorrected). Nonsignificant electrodes ( $p>0.05$ ) are masked in dark blue, significant electrodes are emphasized by large purple discs in the voltage plot. $\boldsymbol{A} \boldsymbol{b}$, Grand average SEPs at channel CP4 for the subthreshold left attended condition. The bottom plot prathreshold stimulation, only showed the expected main effect of amplitude bin $\left(F_{(4,144)}=1264.5, p[\mathrm{GG}]<0.0001, \eta_{G}^{2}=\right.$ $0.44)$. Average bin amplitude values are therefore comparable between attention conditions (except for bin 5 preceding subthreshold stimulation).

To test the relationship between prestimulus mu amplitude and SEP amplitude, we calculated LMM regression fits with both linear and quadratic predictors for each stimulus and attention condition. For suprathreshold stimulation, regressions both for attended and unattended stimulation turned out to be highly significant compared with an intercept-only model (i.e., a model with no relationship assumed, attended: $\chi^{2}=26.01, p=0.0001$; unattended: $\chi^{2}=46.04, p=0.0001$; Table 2, models 9 and 12). As shown in Figure $6 \mathrm{Da}$, the relationship for the attention conditions is reversed: we find a negative quadratic relationship when the stimulated finger is attended and a regular (positive) quadratic relationship when it is unattended. For subthreshold stimulation, we again observe a significant negative quadratic relationship when the stimulated side is attended $\left(\chi^{2}=22.25, p=\right.$ 0.0013; Table 2, model 3), and a positive quadratic relationship when the stimulated side is unattended $\left(\chi^{2}=30.03, p=0.0002\right.$; Table 2, model 6).

We also evaluated the relationship between prestimulus mu amplitude and hit rates for the suprathreshold attended condition, as this is the one condition in that participants responded to perceived stimuli via button press. As for the SEPs in the previous section, we found a significant quadratic relationship compared with the no-relationship (intercept-only) model $\left(\chi^{2}=42.44, p=0.001\right.$; Table 3 , also including the test against a pure linear model).

To test whether tactile attention is solely reflected by the variation of pre-mu, we fitted the data combining both attention con-

$\leftarrow$

shows the SEPs on a zoomed scale for the yellow shaded area of the top plot. Time is expressed relative to stimulus onset (0 ms). Lightly shaded background areas indicate $95 \%$ confidence intervals derived from paired $t$ tests of each data point against mean baseline activity. $\boldsymbol{A c}, \boldsymbol{B} \boldsymbol{a}$, and $\boldsymbol{B} \boldsymbol{c}$ are the same as $A \boldsymbol{a}$ but for the subthreshold left unattended, suprathreshold left attended and suprathreshold left unattended conditions, respectively. Note the different scaling of the ordinate for suprathreshold stimulation. $\boldsymbol{A} \boldsymbol{d}$ is the same as $\boldsymbol{A} \boldsymbol{b}$ but for the subthreshold left unattended condition. $\boldsymbol{B} \boldsymbol{b}$ and $\boldsymbol{B} \boldsymbol{d}$ are the same as $\boldsymbol{A} \boldsymbol{b}$ and $\boldsymbol{A d}$ but for the suprathreshold left attended and suprathreshold left unattended conditions, respectively. Note the different scaling of the ordinate. 


\section{Attended}

\section{Unattended}

\section{subthreshold}

$\mathrm{Aa}$

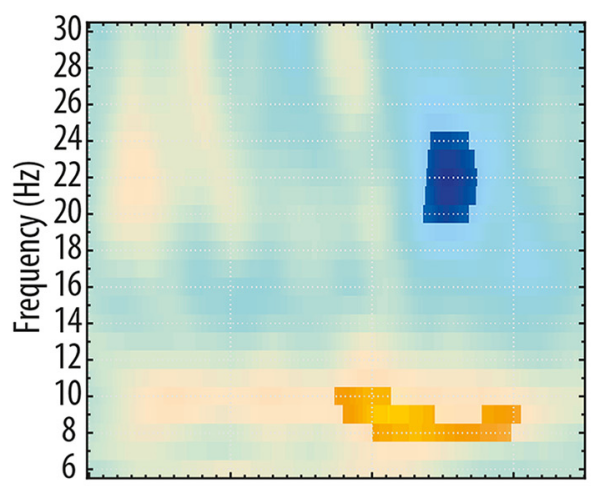

b

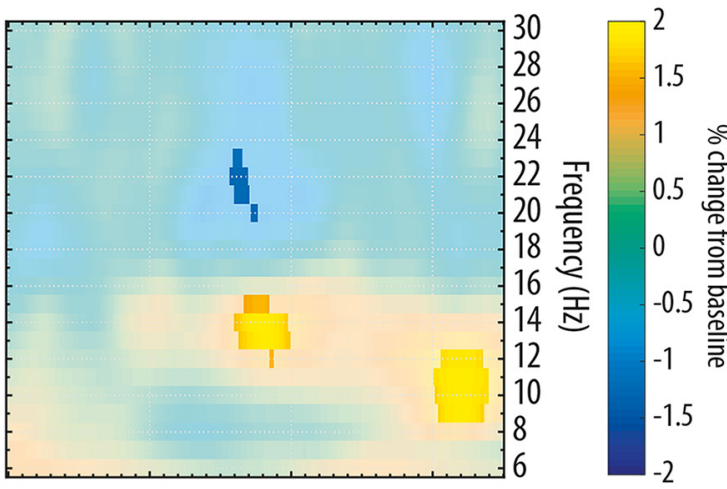

\section{suprathreshold}

$\mathrm{Ba}$

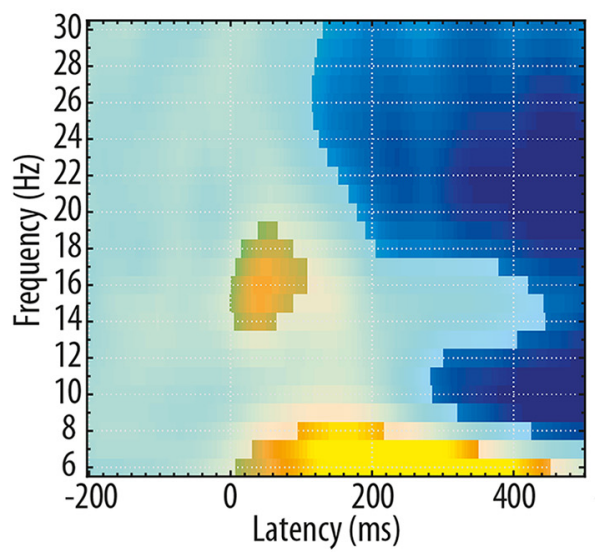

b

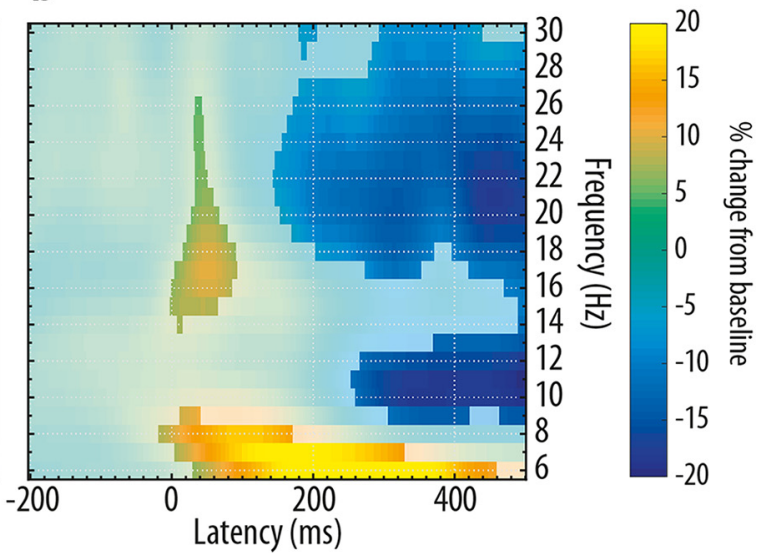

Figure 5. Subthreshold stimulation increases, suprathreshold stimulation decreases Rolandic rhythms. Grand average time frequency plots (contralateral to stimulation side at CP4) for subthreshold $(\boldsymbol{A} \boldsymbol{a}$ and $\boldsymbol{A} \boldsymbol{b})$ and suprathreshold ( $\boldsymbol{B} \boldsymbol{a}$ and $\boldsymbol{B} \boldsymbol{b}$ ) stimulation after selection and forward projection of pericentral independent mu components. Time is expressed relative to stimulation onset, oscillatory activity is expressed relative to baseline amplitude (baseline: -700 to -200 ms prestimulus). Light colored areas did not survive fdr-correction for multiple comparisons at $q=0.05$ (Genovese et al., 2002).

ditions (Fig. 1A, mediator model; for details, see Assessment of the relationship between prestimulus mu amplitude, somatosensoryevoked potential and attention) with the very same model definition as above. For the case where the effect of attention on SEP amplitudes is independent from the effect on pre-mu activity (Fig. $1 B$, independence model), we only included "attention" as fixed effect factor and within-participant factor in the random effects part to model SEP amplitudes across attention conditions. Alternatively, if the relationship between prestimulus mu amplitude and SEP amplitude essentially depends on the actual attention state (Fig. 1C, interaction model), a model with attention included as an interacting factor should better fit the very same dataset. Indeed, a bootstrapped likelihood ratio test revealed the attention interaction model to be significantly more likely than both the mediator and the independence model for both subthreshold and suprathreshold stimulation (Table 4; subthreshold: $\chi^{2}=50.22, p=0.0016$ and $\chi^{2}=45.41, p=0.0001$; suprathreshold: $\chi^{2}=56.94, p=0.024$ and $\chi^{2}=51.4, p=0.0006$, respectively).

\section{Discussion}

In the present study, we investigated (1) whether spatial attention modulates the amplitude of early SEP components in response to electrical left finger nerve stimulation both for suprathreshold and subthreshold intensities, and (2) the role of prestimulus mu activity on this attentional modulation. Together, we found that attention increases the amplitude for the P1 component for both kinds of stimulation. Furthermore, prestimulus mu amplitude (pre-mu) interacts with stimulus related responses. Interestingly, pre-mu activity affects both behavioral responses and evoked brain activity, the latter differentially depending on the attentional state: with spatial attention, there is a negative quadratic relationship between pre-mu and evoked amplitudes, whereas without spatial attention the relationship is positive quadratic. Intermediate and higher mu amplitudes go along with large evoked activity during spatial attention and with small evoked activity without attention.

Sustained attention is widely known to improve perception in a variety of tasks and virtually all modalities (Sathian and Burton, 
A

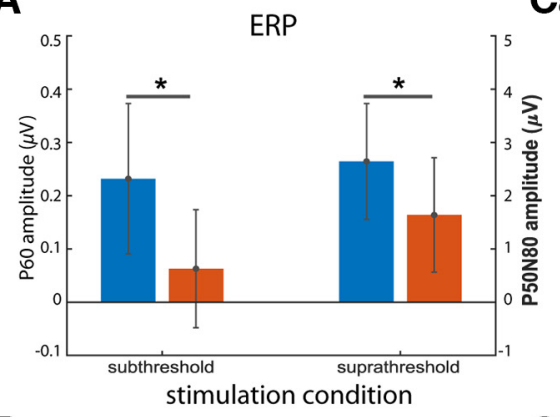

B

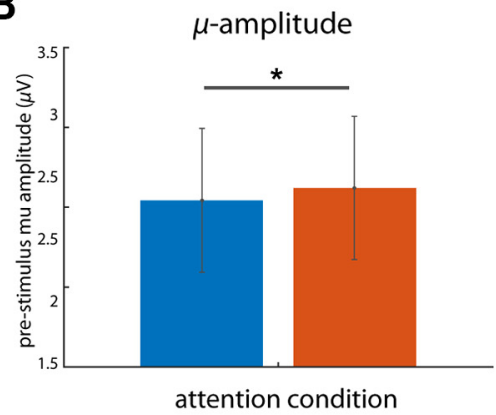

$\mathrm{Ca}$

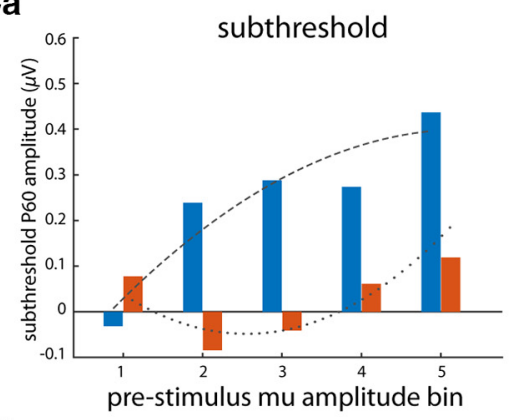

$\mathrm{Cb}$

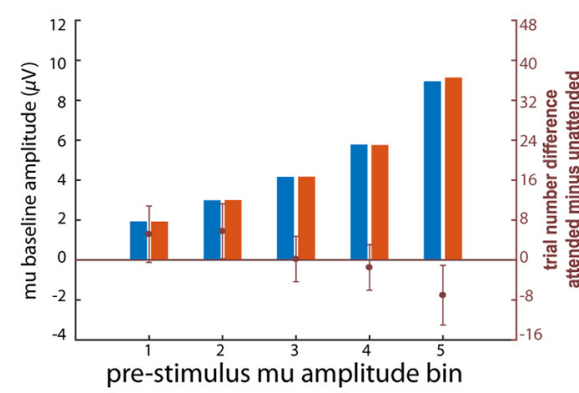

$\mathrm{Da}$

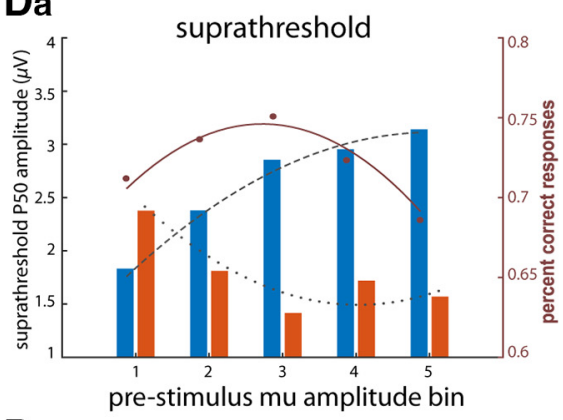

$\mathrm{Db}$

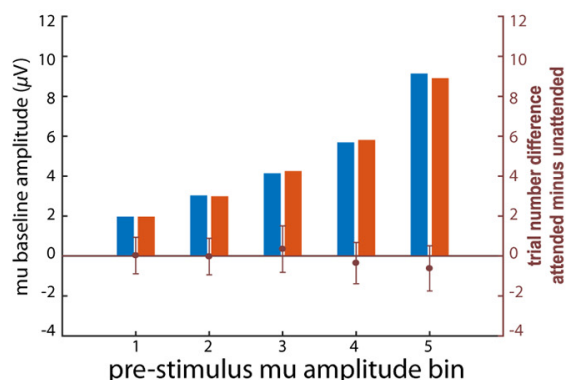

attended unattended $195 \%$-CI

Figure 6. For all subplots, blue and red bars depict the attended and unattended conditions, respectively. $\boldsymbol{A}$, Subthreshold (left) and suprathreshold (right) SEPs and ( $\boldsymbol{B})$ grand-average attention effect for prestimulus mu amplitude ( -1000 to $-200 \mathrm{~ms}$ ). Error bars indicate $95 \%$ confidence intervals of the mean. Asterisks indicate significance at $p<0.05$. C, Subthreshold stimulation: relationship between prestimulus mu and SEP amplitudes $(\boldsymbol{C a})$ and prestimulus mu amplitude values averaged across trials within each bin $(-300$ to $-200 \mathrm{~ms} ; \boldsymbol{C b})$. D, Suprathreshold stimulation: same as C but for the suprathreshold left attended condition. Da, Additionally, red dots show the average hit rates for each mu amplitude bin and the red solid line depicts the fit of the LMM for the suprathreshold left attended condition. Overlaid dashed and dotted lines in C $\boldsymbol{a}$ and $\boldsymbol{D} \boldsymbol{a}$ are fits of the LMM for respective SEP amplitudes. Red dots (with $95 \%$ confidence intervals) in $\boldsymbol{C} \boldsymbol{b}$ and $\boldsymbol{D} \boldsymbol{b}$ depict the difference in absolute number of trials of each mu amplitude bin between attention conditions.

Table 3. LMM testing the relationship between prestimulus mu amplitude bin and HR for the suprathreshold left attended condition (model no. 13-15)

\begin{tabular}{lllll}
\hline Condition & Model No. & Lmer syntax & Likelihood \\
\hline Suprathreshold attended & $(13)$ & HR $\sim 1+(1 \mid$ Subject $)$ & 73.02 & LRT \\
& $(14)$ & $H R \sim 1+$ Bin $+(1+$ Bin|Subject $)$ & 82.8 & $\chi^{2}=19.57^{* * *}$ \\
& $(15)$ & $H R \sim 1+$ Bin + I(Bin^2)+(1+Bin + I(Bin^2)|Subject) & 94.23 & $\chi^{2}=22.87^{* * *}$ \\
\hline
\end{tabular}

Models are evaluated as in Table 2 (bootstrapped $p$ values are based on 10,000 simulations): ${ }^{*}<0.05-0.01,{ }^{* *}<0.01-0.001, * * * 0.001-0$.

Table 4. LMM testing the relationship between prestimulus mu amplitude bin and SEP amplitude for datasets that combine both attention conditions (model no. 16-21; Fig. 1A-C)

\begin{tabular}{|c|c|c|c|c|}
\hline Condition & Model №. & Lmer syntax & Likelihood & LRT \\
\hline $\begin{array}{l}\text { Subthreshold, both } \\
\text { attention conditions }\end{array}$ & $\begin{array}{l}(16) \\
(17) \\
(18)\end{array}$ & 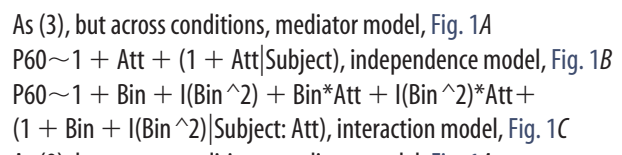 & $\begin{array}{l}-355.71 \\
-353.3 \\
-330.6\end{array}$ & $\begin{array}{l}\text { (17) } \chi^{2}=-4.8 \\
\text { (16) } \chi^{2}=50.22^{* *} \\
\text { (17) } \chi^{2}=45.41^{* * *}\end{array}$ \\
\hline $\begin{array}{l}\text { Suprathreshold, both } \\
\text { attention conditions }\end{array}$ & $\begin{array}{l}(19) \\
(20) \\
(21)\end{array}$ & 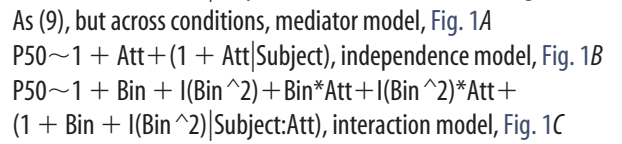 & $\begin{array}{l}-894.7 \\
-891.93 \\
-866.23\end{array}$ & $\begin{array}{l}\text { (20) } \chi^{2}=-5.5 \\
\text { (19) } \chi^{2}=56.94^{* a} \\
\text { (20) } \chi^{2}=51.4^{* * *}\end{array}$ \\
\hline
\end{tabular}

The interaction model is compared with the two smaller models (mediator model and independence model, indicated by the model number given in the LRT column). Parametric bootstrapping was based on 10,000 simulations: ${ }^{*}<$ $0.05-0.01,{ }^{* *}<0.01-0.001,{ }^{* * *}<0.001-0$.

${ }^{a}$ For this test, we doubled the number of simulations, because the $p$ value based on 10,000 simulations marginally missed significance $(p=0.058)$.

1991; Spence and Driver, 1994; Marks and Wheeler, 1998; Kastner et al., 1999; Spence et al., 2000, 2001; Carrasco, 2011). The deployment of attentional resources should facilitate perception to any task relevant sensory input as long as it proceeds along the same bottom-up somatosensory pathway (Dehaene et al., 2006; Kiefer, 2012; Schröger et al., 2015). Whether this also holds for subthreshold stimuli, however, is not known, because noninvasive recordings of evoked activity to unmasked subthreshold stimulation have been obtained in only a few studies (somatosensation:
Nierhaus et al., 2015; vision: Bareither et al., 2014; Sperdin et al., 2014) and did not investigate attentional modulation. Our results clearly support this postulate by showing an increase in the P1 amplitude with spatial attention, $60 \mathrm{~ms}$ after stimulation. This effect coincides with an attention effect in the same time range (P50-N80) for suprathreshold stimulation as it has been shown previously (Michie et al., 1987). However, evidence regarding the effect of attention on P1 is ambiguous, because Schubert et al. (2008) found the attention effect on P1 only on one side (left but 
not right) and Zopf et al. (2004) did not find it at all. Interestingly, in our study, the attentional modulation of P1 was most clearly evident in the interaction between attention, pre-mu activity, and SEP, and the observed nonlinear relationship between mu and P1 might explain why the effect of attention on P1 has not been seen in some previous studies. Future studies need to show whether this is also true for right index finger stimulation, for which perceptual difference have been reported (Meador et al., 1998).

As we reported previously (Nierhaus et al., 2015), upon subthreshold stimulation we did not observe any further ERP component beyond P1. However, a transient increase of mu amplitude has been observed after subthreshold stimulation (Fig. 5), which contrasts the poststimulus decrease typically seen after externally triggered near- and suprathreshold stimulation (Pfurtscheller, 1989; Nikouline et al., 2000a; Palva et al., 2005; Nierhaus et al., 2015). Generally speaking, increases in mu amplitude may be induced by the feedforward inhibition associated with subthreshold stimulation as we have discussed previously (Blankenburg et al., 2003; Taskin et al., 2008; Nierhaus et al., 2015).

With respect to the attention effect on pre-mu activity, our results are in line with several studies reporting that attention leads to a decrease of alpha power contralateral to where spatial attention is directed compared with ipsilateral sites (somatosensory: Pfurtscheller and Lopes da Silva, 1999; Jones et al., 2010; Anderson and Ding, 2011; Haegens et al., 2011a, 2012; visually: Thut et al., 2006; auditory: Weisz et al., 2014; Wöstmann et al., 2016). This strongly supports the assumption of selective attention relying on intrinsic oscillatory activity in the somatosensory cortex already before the incoming stimulus (Thut et al., 2006).

Regarding the relationship between pre-mu activity and perceptual performance, we show detection rates to be largest for intermediate pre-mu and lowest for either minimal or maximal pre-mu, which is in line with previous research reporting inverse U-shaped relationships (Linkenkaer-Hansen et al., 2004; Zhang and Ding, 2010). Consistent with this, some studies reported a comodulation of prestimulus mu activity and early SEP components in response to near- and suprathreshold electrical stimuli (Zhang and Ding, 2010; Anderson and Ding, 2011), both cases exhibiting an inverted $\mathrm{U}$-shaped relationship between prestimulus mu power and the respective N1.

Contrasting two alpha power ranges (e.g., "high" and "low") can allow only for describing linear effects as done in other studies. Here, we extracted five bins of pre-mu that resulted in comparable mu amplitudes between attention conditions for each bin (Fig. $6 C b, D b$ ). We observe a nonlinear influence of pre-mu activity on P1 amplitudes for both attention conditions, which is in line with the findings of Zhang and Ding (2010) and Anderson and Ding (2011). Moreover, we find that the very same alpha amplitudes (intermediate to highest) are related to the highest SEP amplitudes under attention but also to the lowest SEP amplitudes during inattention. Thus, attention might alter the functional relationship between pre-mu activity and stimulus-related processing (SEP components) according to the task requirements. Rather than serving the deployment of attention alone, mu activity may maximize evoked activity related to the "to-beattended" stimulus (facilitation), but at the same time minimizes evoked neural processing related to the "to-be-unattended" stimulus (suppression).

At a first glance, this interpretation seems to contradict the initial hypothesis that alpha mediates the effect of attention: the very same pre-mu activity would convey the same attentional influence, and the relation between pre-mu activity and SEP amplitude would not be differentiable between the two attention conditions. Indeed, a different role for alpha has been suggested in recent studies, which indicate that it might reflect the expectation of upcoming events (Bauer et al., 2014; Sedley et al., 2016) rather than attention (Zhang and Ding, 2010; Anderson and Ding, 2011; Foxe and Snyder, 2011). However, in our study neither frequency nor timing of an upcoming perceivable event differed between attention conditions, so it is very unlikely that the differential influence of mu activity on SEP amplitudes with respect to attention reflects differences in expectation. Admittedly, individual variations in the ability to predict an upcoming stimulation within a certain attentional state, which then might be related to different pre-mu activity, cannot be excluded. Whether this holds true also for subthreshold stimulation is an interesting question, which we address by experimentally manipulating both attention and expectation in the future.

Second, the underlying local spatial pattern of alpha distribution across the cortex might differ between the two conditions, which is possibly smeared given the limited spatial resolution of EEG (Lopes da Silva et al., 1976; Suffczynski et al., 2001; Palva and Palva, 2007). For the visual cortex it is well established that selective attention to a certain location or stimulus feature enhances the response of the coding receptive field while suppressing the immediate surrounding and leaving the further surrounding unaffected (Harvey et al., 2013). This is known as the "Mexican hat" distribution of selective attention (Müller and Kleinschmidt, 2004; Müller et al., 2005; Treue, 2014). Such a distribution improves the internal signal-to-noise ratio and could explain why the attention-mu relationship is not linear in our case: the mu rhythm (based on ICA) that was measured over an electrode (CP4) contralateral to the stimulation site is most probably a compound of rhythmic activities in adjacent brain areas. Thus, the intermediate overall mu amplitude may reflect a balance between decreased mu in the brain regions representing the receptive field of the attended finger (facilitation) and increased $\mathrm{mu}$ in adjacent topological fields (surround suppression; Suffczynski et al., 2001). Interestingly, this framework predicts smallest SEP amplitudes for intermediate mu activity as a consequence of compound rhythmic activities originating from adjacent brain areas: the response of the to-be-ignored receptive field is suppressed, thereby exhibiting higher mu activity while at the same time adjacent fields might be less suppressed. Following this concept, the effect of attention is in fact mediated by mu activity, albeit on a more local spatial scale than can be resolved with the common EEG approach. In future studies, simultaneous EEG-fMRI (in which the fMRI correlate of mu rhythm is expected to differ between the different attention conditions) or invasive electrocorticography may help to elucidate this question.

In conclusion, our results show that although access to conscious perception is prevented, attention nevertheless affects neural processing of subthreshold stimuli in a top-down manner as it does for suprathreshold stimuli. Furthermore, prestimulus $\mathrm{mu}$ activity differentially influences neural processing to enable optimal performance in a given task and we suggest this to be a general neural signature for attentional deployment as it encompasses both conscious and unconscious perception.

\section{References}

Alho K, Medvedev SV, Pakhomov SV, Roudas MS, Tervaniemi M, Reinikainen K, Zeffiro T, Näätänen R (1999) Selective tuning of the left and right auditory cortices during spatially directed attention. Brain Res Cogn Brain Res 7:335-341. CrossRef Medline

Anderson KL, Ding M (2011) Attentional modulation of the somatosensory mu rhythm. Neuroscience 180:165-180. CrossRef Medline

Baayen RH, Davidson DJ, Bates DM (2008) Mixed-effects modeling with 
crossed random effects for subjects and items. J Mem Lang 59:390-412. CrossRef

Bakeman R (2005) Recommended effect size statistics for repeated measures designs. Behav Res Methods 37:379-384. CrossRef Medline

Bareither I, Chaumon M, Bernasconi F, Villringer A, Busch NA (2014) Invisible visual stimuli elicit increases in alpha-band power. J Neurophysiol 112:1082-1090. CrossRef Medline

Barr DJ, Levy R, Scheepers C, Tily HJ (2013) Random effects structure for confirmatory hypothesis testing: keep it maximal. J Mem Lang 68:255278. CrossRef

Bates D, Mächler M, Bolker B, Walker S (2014) Fitting linear mixed-effects models using lme4. J Stat Software 67:1-48. CrossRef

Bauer M, Stenner MP, Friston KJ, Dolan RJ (2014) Attentional modulation of alpha/beta and gamma oscillations reflect functionally distinct processes. J Neurosci 34:16117-16125. CrossRef Medline

Bekhtereva V, Sander C, Forschack N, Olbrich S, Hegerl U, Müller MM (2014) Effects of EEG-vigilance regulation patterns on early perceptual processes in human visual cortex. Clin Neurophysiol 125:98-107. CrossRef Medline

Blankenburg F, Taskin B, Ruben J, Moosmann M, Ritter P, Curio G, Villringer A (2003) Imperceptible stimuli and sensory processing impediment. Science 299:1864. CrossRef Medline

van Boxtel JJ, Tsuchiya N, Koch C (2010) Opposing effects of attention and consciousness on afterimages. Proc Natl Acad Sci U S A 107:8883-8888. CrossRef Medline

Carrasco M (2011) Visual attention: the past 25 years. Vision Res 51:14841525. CrossRef Medline

Clayton MS, Yeung N, Cohen Kadosh R (2015) The roles of cortical oscillations in sustained attention. Trends Cogn Sci 19:188-195. CrossRef Medline

de Haan B, Stoll T, Karnath HO (2015) Early sensory processing in right hemispheric stroke patients with and without extinction. Neuropsychologia 73:141-150. CrossRef Medline

Dehaene S, Changeux JP, Naccache L, Sackur J, Sergent C (2006) Conscious, preconscious, and subliminal processing: a testable taxonomy. Trends Cogn Sci 10:204-211. CrossRef Medline

Delorme A, Makeig S (2004) EEGLAB: an open source toolbox for analysis of single-trial EEG dynamics including independent component analysis. J Neurosci Methods 134:9-21. CrossRef Medline

Delorme A, Sejnowski T, Makeig S (2007) Enhanced detection of artifacts in EEG data using higher-order statistics and independent component analysis. Neuroimage 34:1443-1449. CrossRef Medline

Delorme A, Palmer J, Onton J, Oostenveld R, Makeig S (2012) Independent EEG sources are dipolar. PLoS One 7:e30135. CrossRef Medline

Desmedt JE, Robertson D (1977) Differential enhancement of early and late components of the cerebral somatosensory evoked potentials during forced-paced cognitive tasks in man. J Physiol 271:761-782. CrossRef Medline

Eason RG, Harter MR, White CT (1969) Effects of attention and arousal on visually evoked cortical potentials and reaction time in man. Physiol Behav 4:283-289. CrossRef

Fahrenfort JJ, Scholte HS, Lamme VA (2007) Masking disrupts reentrant processing in human visual cortex. J Cogn Neurosci 19:1488-1497. CrossRef Medline

Foxe JJ, Snyder AC (2011) The role of alpha-band brain oscillations as a sensory suppression mechanism during selective attention. Front Psychol 2:154. CrossRef Medline

Gandhi SP, Heeger DJ, Boynton GM (1999) Spatial attention affects brain activity in human primary visual cortex. Proc Natl Acad Sci U S A 96: 3314-3319. CrossRef Medline

Genovese CR, Lazar NA, Nichols T (2002) Thresholding of statistical maps in functional neuroimaging using the false discovery rate. Neuroimage 15:870-878. CrossRef Medline

Goltz D, Pleger B, Thiel SD, Villringer A, Müller MM (2013) Sustained spatial attention to vibrotactile stimulation in the flutter range: relevant brain regions and their interaction. PLoS One 8:e84196. CrossRef Medline

Goltz D, Gundlach C, Nierhaus T, Villringer A, Müller M, Pleger B (2015) Connections between intraparietal sulcus and a sensorimotor network underpin sustained tactile attention. J Neurosci 35:7938-7949. CrossRef Medline

Graziano MSA (2013) Consciousness and the social brain. Oxford, UK: Oxford UP.
Haegens S, Händel BF, Jensen O (2011a) Top-down controlled alpha band activity in somatosensory areas determines behavioral performance in a discrimination task. J Neurosci 31:5197-5204. CrossRef Medline

Haegens S, Nácher V, Luna R, Romo R, Jensen O (2011b) $\alpha$-oscillations in the monkey sensorimotor network influence discrimination performance by rhythmical inhibition of neuronal spiking. Proc Natl Acad Sci U S A 108:19377-19382. CrossRef Medline

Haegens S, Luther L, Jensen O (2012) Somatosensory anticipatory alpha activity increases to suppress distracting input. J Cogn Neurosci 24:677685. CrossRef Medline

Halekoh U, Højsgaard S (2014) A Kenward-Roger approximation and parametric bootstrap methods for tests in linear mixed models: the $R$ package pbkrtest. J Stat Software 59:1-32. CrossRef

Harvey BM, Vansteensel MJ, Ferrier CH, Petridou N, Zuiderbaan W, Aarnoutse EJ, Bleichner MG, Dijkerman HC, van Zandvoort MJ, Leijten FS, Ramsey NF, Dumoulin SO (2013) Frequency specific spatial interactions in human electrocorticography: V1 alpha oscillations reflect surround suppression. Neuroimage 65:424-432. CrossRef Medline

Hautus MJ (1995) Corrections for extreme proportions and their biasing effects on estimated values of $d^{\prime}$. Behav Res Methods Instr Comput 27: 46-51. CrossRef

Hillyard SA, Hink RF, Schwent VL, Picton TW (1973) Electrical signs of selective attention in the human brain. Science 182:177-180. CrossRef Medline

Jensen O, Mazaheri A (2010) Shaping functional architecture by oscillatory alpha activity: gating by inhibition. Front Hum Neurosci 4:186. CrossRef Medline

Jensen O, Bonnefond M, VanRullen R (2012) An oscillatory mechanism for prioritizing salient unattended stimuli. Trends Cogn Sci 16:200-206. CrossRef Medline

Johansen-Berg H, Christensen V, Woolrich M, Matthews PM (2000) Attention to touch modulates activity in both primary and secondary somatosensory areas. Neuroreport 11:1237-1241. CrossRef Medline

Jones SR, Kerr CE, Wan Q, Pritchett DL, Hämäläinen M, Moore CI (2010) Cued spatial attention drives functionally relevant modulation of the mu rhythm in primary somatosensory cortex. J Neurosci 30:13760-13765. CrossRef Medline

Kastner S, Pinsk MA, De Weerd P, Desimone R, Ungerleider LG (1999) Increased activity in human visual cortex during directed attention in the absence of visual stimulation. Neuron 22:751-761. CrossRef Medline

Kentridge RW, Nijboer TC, Heywood CA (2008) Attended but unseen: visual attention is not sufficient for visual awareness. Neuropsychologia 46:864-869. CrossRef Medline

Kiefer M (2012) Executive control over unconscious cognition: attentional sensitization of unconscious information processing. Front Hum Neurosci 6:61. CrossRef Medline

Kingdom FA, Prins N (2009) Psychophysics: a practical introduction. London: Academic.

Koch C, Tsuchiya N (2007) Attention and consciousness: two distinct brain processes. Trends Cogn Sci 11:16-22. CrossRef Medline

Lamme VA, Zipser K, Spekreijse H (2002) Masking interrupts figureground signals in V1. J Cogn Neurosci 14:1044-1053. CrossRef Medline

Li Y, Ma Z, Lu W, Li Y (2006) Automatic removal of the eye blink artifact from EEG using an ICA-based template matching approach. Physiol Meas 27:425-436. CrossRef Medline

Libet B, Alberts WW, Wright EW Jr, Feinstein B (1967) Responses of human somatosensory cortex to stimuli below threshold for conscious sensation. Science 158:1597-1600. CrossRef Medline

Linkenkaer-Hansen K, Nikulin VV, Palva S, Ilmoniemi RJ, Palva JM (2004) Prestimulus oscillations enhance psychophysical performance in humans. J Neurosci 24:10186-10190. CrossRef Medline

Lopes da Silva FH, van Rotterdam A, Barts P, van Heusden E, Burr W (1976) Models of neuronal populations: the basic mechanisms of rhythmicity. In: Progress in Brain Research, Vol 45 (Corner MA and Swaab DF, eds), pp 281-308. London: Elsevier.

Marks LE, Wheeler ME (1998) Focused attention and the detectability of weak gustatory stimuli: empirical measurement and computer simulations. Ann N Y Acad Sci 855:645-647. CrossRef Medline

Meador KJ, Ray PG, Day L, Ghelani H, Loring DW (1998) Physiology of somatosensory perception: cerebral lateralization and extinction. Neurology 51:721-727. CrossRef Medline

Michie PT, Bearpark HM, Crawford JM, Glue LC (1987) The effects of spa- 
tial selective attention on the somatosensory event-related potential. Psychophysiology 24:449-463. CrossRef Medline

Müller NG, Kleinschmidt A (2004) The attentional "spotlight's" penumbra: center-surround modulation in striate cortex. Neuroreport 15:977-980. CrossRef Medline

Müller NG, Mollenhauer M, Rösler A, Kleinschmidt A (2005) The attentional field has a Mexican hat distribution. Vision Res 45:1129-1137. CrossRef Medline

Nierhaus T, Forschack N, Piper SK, Holtze S, Krause T, Taskin B, Long X, Stelzer J, Margulies DS, Steinbrink J, Villringer A (2015) Imperceptible somatosensory stimulation alters sensorimotor background rhythm and connectivity. J Neurosci 35:5917-5925. CrossRef Medline

Nikouline VV, Linkenkaer-Hansen K, Wikström H, Kesäniemi M, Antonova EV, Ilmoniemi RJ, Huttunen J (2000a) Dynamics of mu-rhythm suppression caused by median nerve stimulation: a magnetoencephalographic study in human subjects. Neurosci Lett 294:163-166. CrossRef Medline

Nikouline VV, Wikström H, Linkenkaer-Hansen K, Kesäniemi M, Ilmoniemi RJ, Huttunen J (2000b) Somatosensory evoked magnetic fields: relation to pre-stimulus mu rhythm. Clin Neurophysiol 111:1227-1233. CrossRef Medline

Oldfield RC (1971) The assessment and analysis of handedness: the Edinburgh inventory. Neuropsychologia 9:97-113. CrossRef Medline

Palva S, Palva JM (2007) New vistas for $\alpha$-frequency band oscillations. Trends Neurosci 30:150-158. CrossRef Medline

Palva S, Linkenkaer-Hansen K, Näätänen R, Palva JM (2005) Early neural correlates of conscious somatosensory perception. J Neurosci 25:52485258. CrossRef Medline

Pfurtscheller G (1989) Functional topography during sensorimotor activation studied with event-related desynchronization mapping. J Clin Neurophysiol 6:75-84. CrossRef Medline

Pfurtscheller G, Lopes da Silva FH (1999) Event-related EEG/MEG synchronization and desynchronization: basic principles. Clin Neurophysiol 110:1842-1857. CrossRef Medline

R Core Team (2014) R: a language and environment for statistical computing. Vienna: R Foundation for Statistical Computing.

Ray PG, Meador KJ, Smith JR, Wheless JW, Sittenfeld M, Clifton GL (1999) Physiology of perception: cortical stimulation and recording in humans. Neurology 52:1044-1049. CrossRef Medline

Reinacher M, Becker R, Villringer A, Ritter P (2009) Oscillatory brain states interact with late cognitive components of the somatosensory evoked potential. J Neurosci Methods 183:49-56. CrossRef Medline

Roberts DM, Fedota JR, Buzzell GA, Parasuraman R, McDonald CG (2014) Prestimulus oscillations in the alpha band of the EEG are modulated by the difficulty of feature discrimination and predict activation of a sensory discrimination process. J Cogn Neurosci 26:1615-1628. CrossRef Medline

Sathian K, Burton H (1991) The role of spatially selective attention in the tactile perception of texture. Percept Psychophys 50:237-248. CrossRef Medline

Schröger E, Marzecová A, SanMiguel I (2015) Attention and prediction in human audition: a lesson from cognitive psychophysiology. Eur J Neurosci 41:641-664. CrossRef Medline

Schubert R, Ritter P, Wüstenberg T, Preuschhof C, Curio G, Sommer W, Villringer A (2008) Spatial attention related SEP amplitude modulations covary with BOLD signal in S1: a simultaneous EEG-fMRI study. Cereb Cortex 18:2686-2700. CrossRef Medline
Sedley W, Gander PE, Kumar S, Kovach CK, Oya H, Kawasaki H, Howard MA, Griffiths TD (2016) Neural signatures of perceptual inference. eLife 5:e11476. CrossRef Medline

Spence CJ, Driver J (1994) Covert spatial orienting in audition: exogenous and endogenous mechanisms. J Exp Psychol Hum Percept Perform 20: 555. CrossRef

Spence C, Pavani F, Driver J (2000) Crossmodal links between vision and touch in covert endogenous spatial attention. J Exp Psychol Hum Percept Perform 26:1298-1319. CrossRef Medline

Spence C, Kettenmann B, Kobal G, McGlone FP (2001) Shared attentional resources for processing visual and chemosensory information. Q J Exp Psychol A 54:775-783. CrossRef Medline

Sperdin HF, Spierer L, Becker R, Michel CM, Landis T (2015) Submillisecond unmasked subliminal visual stimuli evoke electrical brain responses. Hum Brain Mapp 36:1470-1483. CrossRef Medline

Suffczynski P, Kalitzin S, Pfurtscheller G, Lopes da Silva FH (2001) Computational model of thalamo-cortical networks: dynamical control of alpha rhythms in relation to focal attention. Int J Psychophysiol 43:25-40. CrossRef Medline

Summerfield C, Egner T (2014) Attention and decision-making. In: The Oxford Handbook of Attention (Nobre AC and Kaster S, eds). Oxoford: Oxford UP.

Taskin B, Holtze S, Krause T, Villringer A (2008) Inhibitory impact of subliminal electrical finger stimulation on SI representation and perceptual sensitivity of an adjacent finger. Neuroimage 39:1307-1313. CrossRef Medline

Thut G, Nietzel A, Brandt SA, Pascual-Leone A (2006) $\alpha$-Band electroencephalographic activity over occipital cortex indexes visuospatial attention bias and predicts visual target detection. J Neurosci 26:9494-9502. CrossRef Medline

Treue S (2014) Attentional selection: Mexican hats everywhere. Curr Biol 24:R838-R839. CrossRef Medline

Watanabe M, Cheng K, Murayama Y, Ueno K, Asamizuya T, Tanaka K, Logothetis N (2011) Attention but not awareness modulates the BOLD signal in the human V1 during binocular suppression. Science 334:829 831. CrossRef Medline

Weisz N, Müller N, Jatzev S, Bertrand O (2014) Oscillatory alpha modulations in right auditory regions reflect the validity of acoustic cues in an auditory spatial attention task. Cereb Cortex 24:2579-2590. CrossRef Medline

Widmann A, Schröger E, Maess B (2015) Digital filter design for electrophysiological data: a practical approach. J Neurosci Methods 250:34-46. CrossRef Medline

Wöstmann M, Herrmann B, Maess B, Obleser J (2016) Spatiotemporal dynamics of auditory attention synchronize with speech. Proc Natl Acad Sci U S A 113:3873-3878. CrossRef Medline

Wu CT, Weissman DH, Roberts KC, Woldorff MG (2007) The neural circuitry underlying the executive control of auditory spatial attention. Brain Res 1134:187-198. CrossRef Medline

Zhang Y, Ding M (2010) Detection of a weak somatosensory stimulus: role of the prestimulus mu rhythm and its top-Down modulation. J Cogn Neurosci 22:307-322. CrossRef Medline

Zopf R, Giabbiconi CM, Gruber T, Müller MM (2004) Attentional modulation of the human somatosensory-evoked potential in a trial-by-trial spatial cueing and sustained spatial attention task measured with high density 128 channels EEG. Brain Res Cogn Brain Res 20:491-509. CrossRef Medline 